\title{
The Spatial-temporal Variation of Precipitation and Temperature in Xinjiang in Recent 50 Years
}

\author{
Yuzhu Wang ${ }^{\mathrm{a}, \mathrm{b}}$, Haowen Yan ${ }^{\mathrm{a}, \mathrm{b}}$ *, Xiaoping Wang ${ }^{\mathrm{a}, \mathrm{b}}$, Zhuo Wang ${ }^{\mathrm{a}, \mathrm{b}}$ \\ ${ }^{a}$ Faculty of Geomatics, Lanzhou Jiaotong University, Lanzhou 730070, China, 553267213@qq.com, H. \\ Yan,haowen2010@gmail.com, X.Wang,418781194@qq.com \\ ${ }^{b}$ Gansu Provincial Engineering Laboratory for National Geographic State Monitoring, Lanzhou 730070, China, \\ 553267213@qq.com, H.Yan,haowen2010@gmail.com,X.Wang,418781194@qq.com
}

* Corresponding author: haowen2010@gmail.com

Keywords: precipitation;temperature;trend;change;cycle;Xinjiang

Background and Motivation: Because of its unique geographical conditions (far from the ocean, deep in the inland, surrounded by mountains), Xinjiang has formed a distinct temperate continental climate, which has the characteristics of dryness, less rain and strong evaporation. $26 \%$ of the territory is covered by desert, which belongs to a typical resource-based water shortage area and is extremely sensitive to climate change. Precipitation and temperature, as the key factors to characterize climate change, are the most obvious meteorological indicators to reveal regional climate change. Studying its changing trend is not only of great value to water resources allocation, drought and flood warning, agricultural vulnerability assessment in Xinjiang, but also of great significance to social and economic development and ecological environment protection in Xinjiang.

\section{Abstract:}

Research purpose: To master the spatial-temporal evolution of precipitation and temperature in Xinjiang, and to provide reference for industrial, agricultural and transportation industries in the study area.

Date and Rrsearch methods: Based on monthly precipitation and temperature data of 64 weather stations in Xinjiang in recent 50 years, the spatial-temporal variation of precipitation and temperature were analyzed by the methods of simple linear regression,5-year moving average, radial basis function interpolation, sliding $-\mathrm{t}$ test, accumulated variance analysis, Mann-Kendall and morlet wavelet transform.

\section{Research conclusion:}

(1) The annual average precipitation $(8.65 \mathrm{~mm} / 10 \mathrm{a})$ in Xinjiang showed a significant increasing trend, and the increasing trend in local areas was:Northern Xinjiang $(14.83 \mathrm{~mm} / 10 \mathrm{a})>$ Southern Xinjiang $(7.76 \mathrm{~mm} / 10 \mathrm{a})>$ Eastern Xinjiang $(3.37 \mathrm{~mm} / 10 \mathrm{a})$.
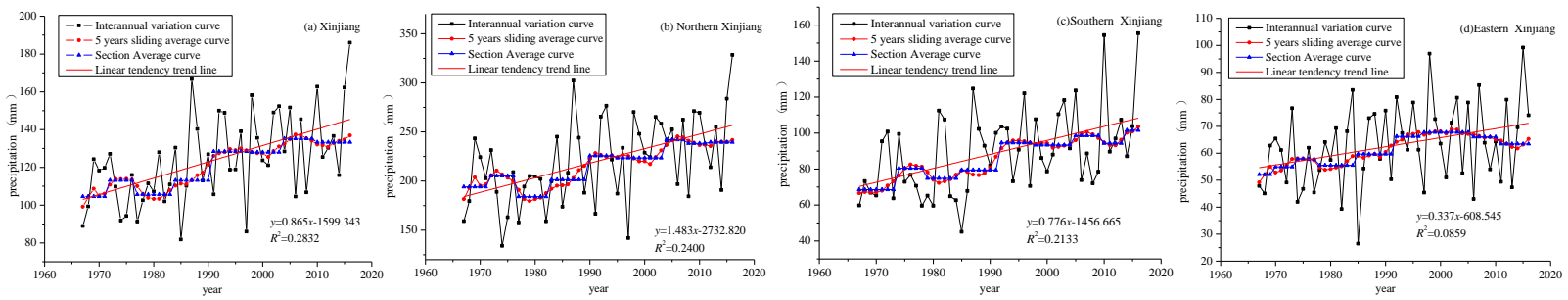

Fig.1 Annual average precipitation in Xinjiang and local areas

(2) The spatial distribution of tendency rate of annual precipitation is basically the same as the spring, summer and autumn in Xinjiang,the tendency rate decreases from northwest to southeast,but the tendency rate of winter precipitation decreases from north to south.

Table.1 Linear tendency rate of annual and seasonal average precipitation in Xinjiang(mm/10a)

\begin{tabular}{cccccc}
\hline Area & Year & Spring & Summer & Autumn & Winter \\
\hline Xinjiang & 8.65 & 1.75 & 3.34 & 1.87 & 1.69 \\
Northern Xinjiang & 14.83 & 2.97 & 5.09 & 2.75 & 4.02 \\
Sorthern Xinjiang & 7.76 & 1.14 & 3.88 & 2.07 & 0.67 \\
Eastern Xinjiang & 3.37 & 1.16 & 1.06 & 0.79 & 0.36 \\
\hline
\end{tabular}

(3) The precipitation of Xinjiang changed abruptly in 1989, Southern Xinjiang was relatively earlier (1986), Northern Xinjiang (1991) and Eastern Xinjiang (1990) were relatively delay. 
Table. 2 Years when the jump of annual and seasonal average precipitation occurred in Xinjiang and local areas

\begin{tabular}{cccccc}
\hline \multirow{2}{*}{ Area } & \multicolumn{5}{c}{ The mutation year of average precipitation } \\
\cline { 2 - 6 } & Year & Spring & Summer & Autumn & Winter \\
\hline Xinjiang & 1989 & 1987 & 1990 & 1986 & 1995 \\
Northern Xinjiang & 1991 & 1997 & 1990 & - & 1991 \\
Southern Xinjiang & 1986 & 1984 & $1986(1995)$ & - & $1978 、 2001$ \\
Eastern Xinjiang & 1990 & 1986 & - & 1976 & $1979 、 1997$ \\
\hline
\end{tabular}

Note: The bracket's value in the table is the mutation year by the method of Mann-Kendall, “___is not obvious for the mutation year.

(4) The main cycle of precipitation was 26-30a in Xinjiang and local areas, which predicts that the next 10 years will be a wet season .

(5) The annual average temperature $\left(0.44{ }^{\circ} \mathrm{C} / 10 \mathrm{a}\right)$ in Xinjiang is very significant, and the temperature increase trend in local areas is: Eastern Xinjiang $\left(0.58^{\circ} \mathrm{C} / 10 \mathrm{a}\right)>$ Northern $\mathrm{Xinjiang}\left(0.45^{\circ} \mathrm{C} / 10 \mathrm{a}\right)>\operatorname{Southern} \mathrm{Xinjiang}\left(0.31{ }^{\circ} \mathrm{C}\right.$ $\mathrm{mm} / 10 \mathrm{a})$.
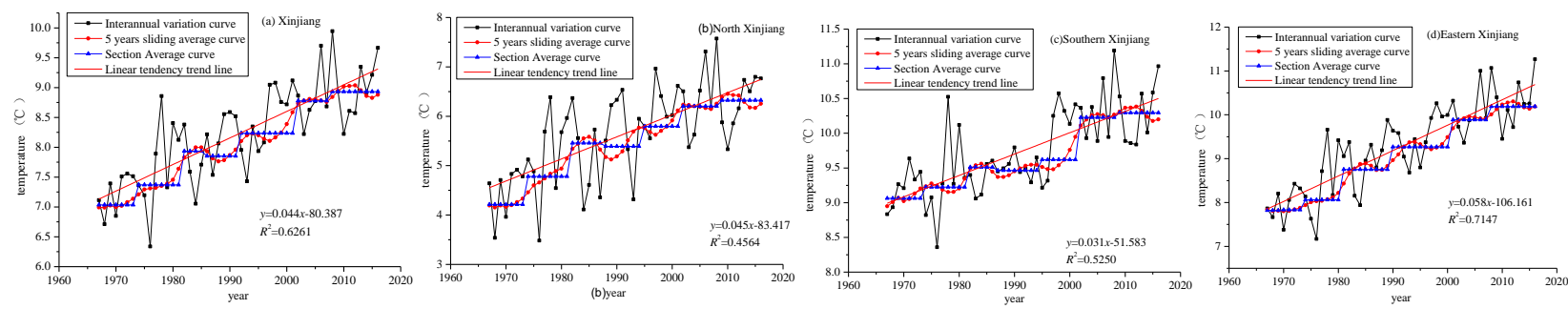

Fig.2 Annual average temperature in Xinjiang and local areas

(6) The spatial distribution of tendency rate of annual average temperature is basically the same as the four seasons in Xinjiang, and the tendency rate showed a decreasing trend from northeast to southwest.

Table.3 Linear tendency rate of annual and seasonal average temperature in $\mathrm{Xinjiang}\left({ }^{\circ} \mathrm{C} / 10 \mathrm{a}\right)$

\begin{tabular}{clllll}
\hline Area & Year & Spring & Summer & Autumn & Winter \\
\hline Xinjiang & 0.44 & 0.48 & 0.36 & 0.44 & 0.50 \\
Northern Xinjiang & 0.45 & 0.52 & 0.3 & 0.44 & 0.52 \\
Southern Xinjiang & 0.31 & 0.31 & 0.22 & 0.31 & 0.4 \\
Eastern Xinjiang & 0.58 & 0.6 & 0.55 & 0.58 & 0.59 \\
\hline
\end{tabular}

(7) The temperature change of Xinjiang occurred in 1988,Northern Xinjiang was 1988 (relatively earlier), Southern Xinjiang and Eastern Xinjiang were 1992 (relatively delay).

Table. 4 Years when the jump of annual and seasonal average temperature occurred in Xinjiang and local areas

\begin{tabular}{cccccc}
\hline \multirow{2}{*}{ Area } & \multicolumn{5}{c}{ The mutation year of average temperature } \\
\cline { 2 - 6 } & Year & Spring & Summer & Autumn & Winter \\
\hline Xinjiang & 1989 & 1999 & 1997 & 1987 & 1980 \\
Northern Xinjiang & 1988 & 2003 & 1996 & 1987 & 1984 \\
Southern Xinjiang & 1992 & 2003 & 1997 & 1993 & 1985 \\
Eastern Xinjiang & 1992 & 1996 & 1996 & 1988 & 1980 \\
\hline
\end{tabular}

(8) The main cycle of temperature in Xinjiang and local areas was 25-30a. It was predicted that the next 10 years would be high temperature period.

\section{Reference}

[1] IPCC. Summary for Policymakers of Climate Change 2013 : The Physical Science Basis : Contribution of working group I to the fifth assessment report of the intergovernmental panel on climate change[M].Cambridge : Cambridge University Press, 2013.

[2] Yin Yunhe, Wu Shaohong, Chen Gang. Regional difference of climate trend and abrupt climate change in China during 1961-2006. Journal of Natural Resources, 2009, 24(12) : 2147-2157. 
[3] Lin Xiang, Qian Weihong. Trends on the daily mean air temperature and its anomalous strength in China for the warm season in the last 40 years. Acta Geographica Sinica, 2003, 58(9) : 21-30.

[4] Shi Yafeng, Shen Junping, Hu Ruji. Preliminary study on signal, impact and foreground of climatic warm-dry to warm-humid in Northwest China. Journal of Glaciology and Geocryology, 2002, 24(3) : 219-226.

[5] Wang Shaowu, Cai Jingning. Climate change of annual precipitation in western China. Journal of Natural Resources, 2002, 17(4) : 415-422.

[6] Li Jianfeng, Zhang Qiang, Bai Yungang4, et al.Spatio-temporal Probability Behaviors of the Maximum Consecutive Wet Days in Xinjiang, China. Acta Geographica Sinica, 2012, 66(3) : 312-320.

[7] Ci Hui, Zhang Qiang, Zhang Jianghui, et al.Spatiotemporal variations of extreme precipitation events within Xinjiang during 1961-2010. Geographical Research, 2014, 33(10) : 1881-1891.1

[8] Pu Zongchao, Zhang Shanqing, et al.WAND Sheng-lanThe Spatial-temporal Variation Characteristic of Dry-wet Climate in Recent 48 Years in Xinj iang Province, China. Journal of Desert Research .2011, 31(6) : 1563-1572.]

[9] LI Jinglin, Zhang Shanqing, Pu Zongchao, et al. Spatial-temporal variation of seasonal and annual air temperature in Xinjiang during 19612010. Arid Land Geography, 2013, 36(2) : 228-237.

[10] Zhang Shanqing, Pu Zongchao, LI Jinglin. The spatial-temporal variation of sunshine duration in Xinjiang during 1961-2010. Acta Geographica Sinica, 2013, 68(11) : 1481-1492.

[11] Yi Xiangsheng, Yin Yanyu, Li Guosheng et al. Temperature variation in recent 50 years in the Three-River Headwaters Region of Qinghai Province. Acta Geographica Sinica, 2011, 66(11) : 1451-1465.

[12] Meng Xiujing, Zhang Shifeng, Zhang Yongyong.The Temporal and Spatial Change of Temperature and Precipitation in Hexi Corridor in Recent 57 Years. Acta Geographica Sinica, 2012, 67(11) : 1482-1492.

[13] Jia Wenxiong.Temporal and Spatial Changes of Precipitation in Qilian Mountains and Hexi Corridor during 1960-2009. Acta Geographica Sinica, 2012, 67(5) : 632-644.

[14] Wei Fengying. Diagnostic and Predictive Technology in Modern Climatologic Statistics. Beijing : China Meteorological Prcss, 1999 : 69-72. 